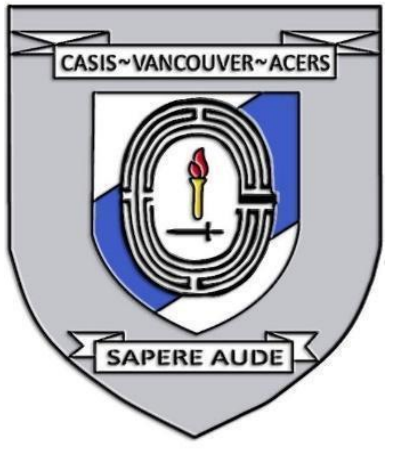

\title{
RADICALIZATION IN THE AGE OF SOCIAL MEDIA: MASS IDENTITY MANIPULATIONS (MIMS)
}

Date: November $25^{\text {th }}, 2020$

This briefing note contains the encapsulation of views presented by the speaker and does not exclusively represent the views of the Canadian Association for Security and Intelligence Studies.

\section{KEY EVENTS}

On November 25, 2020, Dr. Sophia Moskalenko presented on Radicalization in the Age of Social Media: Mass Identity Manipulations (MIMs) at the 2020 CASIS West Coast Security Conference. The presentation was followed by a panel discussion for questions \& answers, and breakout rooms for further discussion before closing off the day. The key topics of Dr. Moskalenko's presentation included social media's role in mass radicalization, MIMs, and the impact of MIMs in radicalization and de-radicalization efforts.

\section{NATURE OF DISCUSSION}

\section{Presentation}

Dr. Moskalenko introduced the concept of MIMs as a possible contributor in mass radicalization and/or de-radicalization through the use of social media.

\section{Question Period}

During the question period, the utilization and impact of symbols on social media were discussed.

\section{BACKGROUND}

\section{Presentation}

The global reach of social media has created an environment where images, symbols, and sounds can quickly and easily be disseminated to masses. Dr. Moskalenko studies mechanisms that may lead to mass radicalization as it appears to be increasing in the US. Hate, martyrdom, and jujitsu politics were mechanisms found to be contributing to mass radicalization. However, there is 
no research indicating how mass radicalization occurred through these mechanisms.

Mass radicalization is not a new concept, but the accessibility of social media and its global platform have created a new dynamic of mass radicalization. The impact is likely to be quicker and reach a wider audience, compared to without social media. Therefore, it could be stated that "social media revolutionized mass radicalization." Further, the ideas shared on social media allow for mass collectives to agree and discount whatever information they may deem appropriate. It is based on emotional appeal rather than factual evidence that supports those ideas. Therefore, mass identities can be easily manipulated.

One way in which mass identities are manipulated and may be appealing to individuals is through the use of symbology. Dr. Moskalenko spoke about MIMs and how they may be used as manipulative symbols to gage the interest of an individual. MIMs include "songs/chants, rumors, collective movement, pictures, symbols, and slogans. MIMs are used as messengers that create a "cognitive simplicity and emotional power" attracting mass identities. There are three main purposes: "(1) bring a mass identity into focus; (2) elicit an emotional response; and (3) bypass critical thinking. An example of a MIM is the slogan "Make America Great Again." This slogan creates unity among mass identities that share a similar emotional response. There are two responses that may be elicited with this slogan, which is either looking to live a better life in America, or it may elude an anger filled response.

MIMs as images create responses that are memorable and create a certain appeal that will likely result in an individual returning to view the image continuously. Research has indicated that images that engage the mind and challenge an individual's way of thinking will likely result in remembering the image. An image's engagement of one's mind and the play on one's emotions is what may make it a memorable MIM. Further, MIM symbols are simplistic ways to illustrate one group against another group; it is the concept of "us versus them." However, as much as MIMs may be used to radicalize, they can also be used to de-radicalize and bring attention to issues occurring around the world that need to be addressed. For example, an image of a small child's body washing up on a beach in Greece led to a Red Cross campaign highlighting the Syrian refugees in Europe. Hence, MIMs are important to understand as they are possibly part of the mass radicalization that appears to be occurring through the use of social media. 


\section{Question Period/Breakout Room}

The expansion of social media creates the perfect environment for MIMs to be distributed and retained by mass identities. Researching the deeper meaning of MIM symbols is vital in learning the importance of their influence on mass identities. During the breakout room, Dr. Moskalenko talked about how conspiracy theories underline radicalization and political science. People's desires are fulfilled by these falsified claims which may make these theories attractive to believe.

\section{KEY POINTS OF DISCUSSION}

- Hate, martyrdom, and jujitsu politics were found to be main mechanisms for mass radicalization.

- Social media has provided a new level of mass radicalization.

- MIMs are used to engage individuals through the use of songs, chants, rumors, collective movements, pictures, symbols, and slogans.

- MIMs are likely to elicit an emotional response, making it likely to be remembered and revisited, therefore, likely contributing to radicalization or de-radicalization.

- Conspiracy theories may fulfil desires which are not based on facts while also contributing to radicalization.

(c) $(1)(9)$

NonCommercial-NoDerivatives 4.0 International License.

(C) (Sophia Moskalenko, 2021)

Published by the Journal of Intelligence, Conflict, and Warfare and Simon Fraser University

Available from: https://jicw.org/ 